\title{
Italian science gains budget boost, still awaits reform
}

Rome. Italy's belt-tightening 1996 budget, subject of fierce parliamentary debate since September, was approved by the Senate late last month with some good news for science. Although most other ministries are being required to cut back, the science ministry, headed by Giorgio Salvini, has been spared. Indeed, some research organizations that had been targeted for significant cuts have even been awarded an increase.

The draft budget still has to be approved by Italy's second legislative chamber, the Chamber of Deputies, before the end of this year. But science administrators are optimistic that the Senate's proposals on science will remain untouched.

According to the figures approved by the Senate, the national research council (CNR) will receive a 5 per cent increase next year, raising its budget to IL1,080 billion (US\$679 million). But, according to Sergio Barabaschi, undersecretary of state for science - who, along with Salvini, defended the science ministry's proposals in the Senate through many long nights of acrimonious debate - the victory is greater than the relatively small increase may imply.

Last year, the 1995 budget proposed by the former government of Silvio Berlusconi forecast that the CNR's funds for 1996 and 1997 would be cut to IL850 billion. Furthermore, even this year, the hostility of some members of parliament to the CNR was demonstrated by a proposed amendment requiring all basic research in Italy to be carried out in universities. But the amendment was defeated.

Part of the 5 per cent increase will pay for CNR's planned expansion of research facilities at Monterotondo, near Rome, designed

\section{Stardust mission will collect comet dust}

Washington. The US National Aeronautics and Space Administration (NASA) has chosen a \$200-million mission to collect samples from a comet as the fourth of its Discovery series of planetary missions. Known as Stardust, the spacecraft will fly past comet Wild-2 in January 2004, photograph its nucleus and trap dust particles with a lightweight aerogel material. The samples will then return to Earth in 2006.

The launch is scheduled for 1999. Principal investigator is Donald Brownlee of the University of Washington in Seattle, and it will be managed by NASA's Jet Propulsion Laboratory. The proposal defeated two other concepts - a solar wind sample return and a Venus atmospheric probe - in competition for Discovery funding.

T. $\mathbf{R}$. to host the new European mouse gene repository (see Nature 374, 296; 1995). The council plans to move several research groups to the site, where they will work alongside four regional groups of the European Molecular Biology Laboratory (EMBL). The increase is also intended to further the transfer of technology from individual CNR research institutes to industry.

The desire to boost technology transfer also partly accounts for the additional IL50 billion proposed in the draft budget to be added to the current IL500 billion budget of the National Agency for New Technology, Energy and the Environment (ENEA). Last year, the agency found itself under attack from the Berlusconi government over allegations of inefficiency and a lack of focus of its activities (see Nature 372, 393; 1994). Its president, the physicist Nicola Cabibbo, has since been concentrating on ways to increase efficiency and accountability of the agency.

Another beneficiary of the increased research budget is the beleaguered Italian Space Agency, ASI, which has been seeking help to meet the substantial overcommitments made during the past decade to the European Space Agency and the US National Aeronautics and Space Administration (NASA), as well as future commitments to the international space station (see Nature 373, 467; 1995).

If the budget is approved, ASI funds will increase from IL 850 billion to IL950 billion next year, and its budget is forecast to rise to $\Pi 1,300$ billion by 1998 . In contrast, support for the National Institute for Nuclear Physics (INFN) is proposed to remain constant next year, at IL470 billion.

Barabaschi says he is pleased that the Senate has passed a reasonable budget for science in times of economic difficulty and that, for the first time, the science ministry has won some flexibility in handling its budget, allowing it to protect a few smaller research institutes whose budgets have been cut.

According to Barabaschi, the Senate's support of science is also reflected in its approval of a 3.5 per cent increase in this year's IL5,400 billion total research and development budget. But, like many members of the scientific community, he also argues that Italy is not yet ready for the sort of increase in spending proposed in 1993 by the former research minister, Umberto Colombo, namely a steady rise in funding from 1.6 per cent to 2 per cent of gross national product.

Italian research, he says, still has many problems to resolve before it is ready to receive a significant increase in funds, and must first demonstrate that it can spend such funds responsibly.

Alison Abbott

Japan launches plans for Moon probe and new satellite vehicle

Tokyo. A more economical satellite launcher and an unmanned Moon probe are among plans set out in a policy paper released last week by the National Space Development Agency of Japan (NASDA), part of the Science and Technology Agency (STA). The release of the NASDA policy paper, the first in six years, has been accompanied by the announcement of a launch date for the first test flight of NASDA's new three-stage solid fuel rocket, the $\mathbf{J 1}$.

The new policy paper calls for greater cost-competitiveness in constructing and launching satellites. It describes plans for development of a new launch vehicle, the H2A, which will provide greater lift more

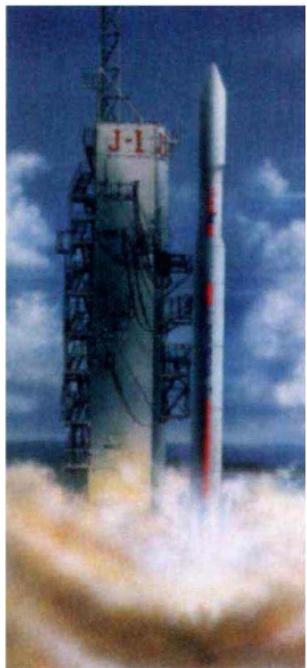

Lift-off: the $\mathbf{J 1}$ has its test flight in February.

2001, will be used to launch the GEM module, Japan's contribution to the international space station.

The new plan calls for the development of an unmanned Moon probe, and for international cooperation on setting up an astronomical observatory on the surface of the Moon. It also suggests that a start should be made on tackling the problem of accumulating man-made garbage in orbit around the Earth.

Although satellite development by NASDA is very advanced technically, it remains commercially uncompetitive, with costs running at more than double those in the United States and Europe. The plan calls for costs to be reduced through subcontracting, using standardized components, and shorter development times.

Low cost and high reliability were the main imperatives behind development of NASDA's new J1 solid fuel rocket, which will make its first test flight on 1 February next year and has been designed to launch small satellites.

Stephen Barker 